\title{
Genetic variations in MyD88 adaptor-like are associated with atopic dermatitis
}

\author{
YANG AN, HIDENORI OHNISHI, EIKO MATSUI, MICHINORI FUNATO, ZENICHIRO KATO, \\ TAKAHIDE TERAMOTO, HIDEO KANEKO, TAKESHI KIMURA, KAZUO KUBOTA, \\ KIMIKO KASAHARA and NAOMI KONDO
}

Department of Pediatrics, Graduate School of Medicine, Gifu University, Gifu, Japan

Received December 9, 2010; Accepted January 20, 2011

DOI: $10.3892 /$ ijmm.2011.645

\begin{abstract}
Toll-like receptors (TLRs) are important pathogenassociated molecular pattern recognition receptors involved in initiating immune responses. The adaptor protein MyD88 adaptor-like (Mal), involved in signaling downstream of TLRs, plays a crucial role in mediating NF- $\kappa \mathrm{B}$ activation. The association of Mal polymorphisms with allergic diseases has not previously been defined. The objective of this study was to detect polymorphisms in the Mal gene and to investigate their association with allergic diseases. Mal gene polymorphisms were genotyped in 310 subjects. The functional effects of Mal variants were analyzed in vitro. One Mal polymorphism, c.303 G>A (Q101Q), was found at a significantly lower frequency in atopic dermatitis patients $(p=0.016)$. Q101Q is in linkage disequilibrium with $-103 \mathrm{~A}>\mathrm{G}$ (rs1893352) and c.539 $\mathrm{C}>\mathrm{T}$ (S180L) (rs8177374) in the HapMap database. The A allele of $-103 \mathrm{~A}>\mathrm{G}$ showed significantly reduced transcription of Mal compared with the $\mathrm{G}$ allele. In addition, three rare variants were identified in this study, c.394 G>A (E132K), c.428 G>A (R143Q) and c.570 G>C (E190D), and were
\end{abstract}

Correspondence to: Dr Eiko Matsui, Department of Pediatrics, Graduate School of Medicine, Gifu University, 1-1 Yanagido, Gifu 501-1193, Japan

E-mail: eikom@gifu-u.ac.jp

Abbreviations: Mal, MyD88 adaptor-like; TIR, Toll/interleukin-1 receptor; TIRAP, Toll/interleukin-1 receptor domain-containing adaptor protein; TLR, Toll-like receptor; PAMPs, pathogen associated molecular patterns; MyD88, myeloid differentiation primary response protein 88 ; TRIF, TIR domain-containing adaptor protein including IFN $\beta$; TRAM, TRIF-related adaptor molecule; IRAK, interleukin-1 receptor-associated kinase; TRAF, tumor necrosis factor receptor-associated factor; $N F-\kappa B$, nuclear factor- $\kappa \mathrm{B}$; IL, interleukin; TNF, tumor necrosis factor; LPS, lipopolysaccharide; SNPs, single nucleotide polymorphisms; NCBI, National Center for Biotechnology Information; LD, linkage disequilibrium; HEK, human embryonic kidney; SD, standard deviation; AD, atopic dermatitis

Key words: atopic dermatitis, innate immunity, Mal/TIRAP, polymorphism, Toll-like receptor shown to lead to loss-of-function of Mal. It is possible that gene polymorphisms in Mal could affect atopic dermatitis by influencing the innate immune system. We show that Q101Q, which is in linkage disequilibrium with $-103 \mathrm{~A}>\mathrm{G}$ and S180L, may play a protective role against atopic dermatitis. Furthermore, we propose that loss-of-function variants of Mal could predispose individuals to atopic dermatitis or other immunological disorders.

\section{Introduction}

The toll-like receptor (TLR) protein family plays a central role in the activation of the innate immune system. In humans, CD14 and TLRs are involved in extracellular recognition of pathogen associated molecular patterns (PAMPs), which activate the initial host defense system. Downstream of the TLRs, five Toll/interleukin-1 receptor (TIR) domain containing adaptor proteins have been identified: myeloid differentiation primary response protein 88 (MyD88), MyD88 adaptor-like (Mal) [also known as Toll/interleukin-1 domaincontaining adaptor protein (TIRAP)], TIR domain-containing adaptor protein including IFN $\beta$ (TRIF), TRIF-related adaptor molecule (TRAM) and sterile $\alpha$ and heat-armadillo motifs. These adaptor proteins function in mediating the intracellular signaling pathways that lead to inflammatory gene expression (1). One of these adaptor proteins, Mal/TIRAP (hereafter referred to as Mal), is involved in the MyD88-dependent signaling pathway downstream of TLR2 and TLR4 $(2,3)$. The Mal/MyD88-dependent signaling pathway induces the sequential activation of interleukin-1 receptor-associated kinase (IRAK)4, IRAK1 and tumor necrosis factor receptorassociated factor-6 (TRAF6) (1). Mal plays specific roles in interactions with various TIR domain-containing adaptors; Mal mediates the interaction between TLR4 and MyD88 $(4,5)$, and directly interacts with the downstream component TRAF6 (6).

Allergic diseases are caused by inappropriate immunological responses to harmless antigens, driven by $\mathrm{T}$ helper type 2 (Th2)-mediated immune responses. Insufficient stimulation of TLRs by PAMPs results in decreased production of T helper type 1 (Th1) cytokines such as, IL-12 and IFNs, which can attenuate the activity of down-regulators of Th2 responses, in turn leading to allergic disease (7). It has been 
Table I. Clinical information on patients with allergic diseases and control subjects.

Patients with allergic diseases $(n=207)$

\begin{tabular}{lccc}
\cline { 2 - 3 } Characteristics & $\mathrm{AD}(\mathrm{n}=99)$ & Other allergic diseases $(\mathrm{n}=108)$ & Control subjects $(\mathrm{n}=103)$ \\
\hline Gender & 62 & 72 & 56 \\
Male & 37 & 36 & 47 \\
Female & & & 38.11 \\
Serum total IgE (IU/ml) & 2491.63 & 950.17 & 21 \\
Mean & 461 & 390 & 39.36 \\
Median & 4835.59 & 1882.37 & 4.34 \\
SD & 2.36 & 1.91 & 152 \\
Min & 24838 & 16000 &
\end{tabular}

$\mathrm{AD}$, atopic dermatitis; $\mathrm{SD}$, standard deviation.

reported that endotoxin can induce MyD88-deficient dendritic cells to support Th2 cell differentiation (8). Therefore, the Mal/MyD88-dependent signaling pathway may be implicated in allergic diseases caused by overactive Th2 responses.

Genetic variations leading to alterations in proteins involved in PAMP recognition or downstream signaling may alter the balance between Th1 and Th2 immune responses and may therefore influence the individual's susceptibility to developing allergic diseases. Previous studies have found single nucleotide polymorphisms (SNPs) in TLRs and TLR-related proteins to be associated with allergic diseases. For example, the polymorphism R753Q in the TLR2 gene increases the frequency of atopic dermatitis $(9,10)$; the A-16934T promoter polymorphism of the TLR2 gene is associated with severe atopic dermatitis (11); polymorphism D299G of the TLR4 gene is associated with a high prevalence of asthma and reduced IL-12 responses (12); and polymorphisms in IRAK4 and promoter polymorphisms of CD14 are associated with total serum IgE levels $(13,14)$.

In contrast to these associations with allergic disease, the Mal polymorphism S180L (rs8177374) has been associated with protection against some diseases (15). However, there is conflicting evidence for the role of S180L in some ethnic populations $(16,17)$. Recently, the rare mutation D96N (rs8177400) was described as a loss-of-function variant of Mal that leads to reduced TLR2/TLR4 signaling activity $(18,19)$. These recent results suggest that the effects of SNPs in Mal are important in some immunological diseases.

In this study, we detected SNPs in the Mal gene in Japanese population samples with or without allergic diseases and explored whether we could detect associations of SNPs with allergic diseases. Further functional analyses were performed to identify the functional effects of the variants of Mal.

\section{Subjects and methods}

Subjects. The association between Mal gene polymorphisms and the presence of atopic dermatitis (AD) $(n=99)$, other allergic diseases $(n=108)$ and non-allergic control subjects $(n=103)$ was analyzed in Japanese subjects. Non-allergic unrelated control subjects had no history of atopic dermatitis or other allergic diseases including bronchial asthma, food allergies, allergic rhinitis or allergic conjunctivitis. Detailed clinical information on the subjects is presented in Table I. The diagnosis of atopic dermatitis was made according to the criteria of Hanifin (20). All subjects provided informed consent to participate in the study.

Polymorphism detection and linkage disequilibrium (LD) analysis. Genomic DNA was extracted from neutrophils using a SepaGene kit (Sanko Junyaku, Tokyo, Japan). Three primer sets (Table II) were designed based on the coding region of the Mal gene sequence available from the National Center for Biotechnology Information (NCBI Reference Sequence: NC_000011.9) to amplify the two coding exons. Genotyping was performed using the ABI 3100 DNA auto-sequencer program (Applied Biosystems). Japanese HapMap data were obtained from http://www.hapmap.org/ (21). Pairwise LD was calculated as the $r^{2}$-values by using the Haploview 4.1 program.

Vector preparation and in vitro mutagenesis. The wild-type coding region of the Mal gene (235-aa isoform; Accession number: NM_148910) was cloned into pFLAG-CMV6a (Sigma-Aldrich). This plasmid was used for generating substituted types of Mal using the GeneEditor in vitro SiteDirected Mutagenesis System (Promega, Madison, WI). Primers containing the following substituted sites in Mal were designed for generating the six different variations of Mal (S55N, Q101Q, E132K, R143Q, S180L and E190D). Fragments (7500-7808 bp of NC_000011.9) contained in the promoter region of Mal and containing the Mal intron 3 replicated from the genome of individuals with or without the $-103 \mathrm{G}$ variation, were cloned into pGL4.11 (luc2P) (Promega). These were used to analyze the transcriptional activities of Mal/-103A and Mal/-103G.

Cell culture. Human embryonic kidney (HEK) 293T cells and 293-hTLR4/MD2-CD14 cells (InvivoGen, CA, USA) were cultured in Dulbecco's modified Eagle's medium (Invitrogen, 
Table II. Primer details for amplifying exon 4 and 5 in the Mal gene by PCR.

\begin{tabular}{|c|c|c|c|c|}
\hline Exon & Primer & Primer sequence & $\begin{array}{c}\text { Length of } \\
\text { amplified DNA }\end{array}$ & $\begin{array}{l}\text { Annealing temp } \\
\left({ }^{\circ} \mathrm{C}\right)\end{array}$ \\
\hline Exon 4 & S4 (F) & 5'GTCTGGCCCTAATCTCATGA3' & & \\
\hline Exon 4 & A4 (R) & 5'САСТСТCСACAAAGCATCCAG3' & 479 bp & 60 \\
\hline Exon 5 & S5 (F) & 5'GAGAATAAGATGTTTCCCAGTGC3' & & \\
\hline Exon 5 & A5 (R) & 5'GCAGCATCTGGTACTTGCACCA3' & $557 \mathrm{bp}$ & 62 \\
\hline Exon 5 & S6 (F) & 5'GGTCTCCTACTTGGAAGGCA3' & & \\
\hline Exon 5 & A6 (R) & 5'CAATGGAAACCTGTTGGTCAG3' & $569 \mathrm{bp}$ & 60 \\
\hline
\end{tabular}

$\mathrm{F}$, forward sense; $\mathrm{R}$, reverse antisense; temp, temperature.

Carlsbad, CA) supplemented with $10 \%$ FCS, $100 \mathrm{U} / \mathrm{ml}$ penicillin and $100 \mathrm{pg} / \mathrm{ml}$ streptomycin. THP-1 cells were cultured in RPMI-1640 medium (Invitrogen) supplemented with $10 \%$ FCS, $0.01 \mathrm{M}$ HEPES, $100 \mathrm{U} / \mathrm{ml}$ penicillin and $100 \mathrm{pg} / \mathrm{ml}$ streptomycin. All cells were incubated at $37^{\circ} \mathrm{C}$ in a humidified atmosphere of $5 \% \mathrm{CO}_{2}$.

Luciferase assay. HEK $293 \mathrm{~T}$ cells $\left(2 \times 10^{4}\right.$ cells/well in 96-well plates) were transfected with $100 \mathrm{ng}$ pFLAG-CMV6a empty vector or pFLAG-CMV6a-Mal wild-type or variants (S55N, Q101Q, E132K, R143Q, S180L and E190D) using Lipofectamine 2000 (Invitrogen). NF- $\kappa \mathrm{B}$ luciferase reporter vector (50 ng) [pGL4.32 (luc2P/NF- $\mathrm{BB}-\mathrm{RE} / \mathrm{Hygro})]$ and $50 \mathrm{ng}$ renilla luciferase reporter control vector (pGL4-hRluc-TK) were co-transfected into the appropriate wells. At $48 \mathrm{~h}$ after transfection, NF- $\kappa \mathrm{B}$ luciferase reporter gene activity was analyzed using the Dual-Luciferase Reporter assay system (Promega). For dose-dependent assays, 293-hTLR4/ MD2-CD14 cells were transfected with 10, 40 and $80 \mathrm{ng}$ plasmids DNA of Mal variants (E132K, R143Q and E190D), respectively. The DNA content was adjusted to a total volume of $80 \mathrm{ng}$ with mock plasmid DNA. Cells were stimulated with lipopolysaccharide (LPS) $(100 \mathrm{ng} / \mathrm{ml})$ for $6 \mathrm{~h}$ and $\mathrm{NF}-\kappa \mathrm{B}$ luciferase reporter gene activity was then analyzed. THP-1 cells are derived from the human monocytic cell line, which expresses TLRs and TLR adaptor proteins. Therefore, we used THP-1 cells to perform transcription activity assays and cytokine production experiments. THP- 1 cells $\left(1 \times 10^{6}\right.$ cells $\left./ \mathrm{ml}\right)$ were transfected using Lipofectamine LTX (Invitrogen) with 800 ng pGL4.11 (luc2P) control vector, pGL4.11 (luc2P)-Mal promoter (-103A) or pGL4.11 (luc2P)-Mal promoter (-103G). pGL4-hRluc-TK (50 ng) was co-transfected into all wells as an internal control. Transcriptional enhancer activities were measured at $24 \mathrm{~h}$ after transfection. Each of the luciferase assays was performed at least three times.

Measurement of TNF- $\alpha$ and IL-12. THP-1 cells $\left(1 \times 10^{6}\right.$ cells $\left./ \mathrm{ml}\right)$ were transfected with Mal variant plasmids as described above or with the pSV- $\beta$-galactosidase control vector as an internal control using Nucleofector (Amaxa, Program V-001). After $24 \mathrm{~h}$ of transfection, cells were cultured with or without $100 \mathrm{ng} / \mathrm{ml}$ LPS for a further $24 \mathrm{~h}$. Supernatants were collected at $48 \mathrm{~h}$ after transfection and the concentrations of TNF- $\alpha$ and IL-12 in the supernatants were determined using human
TNF- $\alpha$ or human IL-12 ELISA kits (BioSource International, Carlsbad, CA).

Western blotting. HEK $293 \mathrm{~T}$ cells $\left(8 \times 10^{5}\right.$ cells/well for 6 -well plates) were transfected as described above. After $48 \mathrm{~h}$, cells were lysed in $200 \mu \mathrm{l}$ lysis buffer $(10 \mathrm{mM}$ Tris $\mathrm{HCl}, \mathrm{pH} 7.5,10 \mathrm{mM} \mathrm{NaCl}, 2 \mathrm{mM}$ EDTA, $10 \%$ glycerol and $1 \%$ Nonidet P-40) containing a protease inhibitor cocktail (Roche, Mannheim, Germany). The concentration of each expressed protein was measured by the Lowry method and the quantity of each expressed protein was adjusted to load equal protein quantities for Western blots analysis. Samples were analyzed by Western blotting using an anti-FLAG M2 monoclonal antibody (Sigma-Aldrich, St. Louis, MO).

Statistical analysis. Genotype frequencies were analyzed using a chi-square $\left(\chi^{2}\right)$ test. A p-value of $<0.05$ was considered statistically significant. The differences in luciferase activities and cytokine values between wild-type Mal and the Mal variants were analyzed using the Dunnett's test. The difference between the transcriptional activity of $-103 \mathrm{~A}$ and $-103 \mathrm{G}$ was analyzed by the Bonferroni test. Each assay was performed with at least three samples.

Protein structure modeling. Structure modeling of the TIR domain of Mal was performed using the MyD88-TIR structure (PDB code: $2 \mathrm{z} 5 \mathrm{v}$ ) as a template on MOE software according to our previously described method (5). The figure of this structure was made using PyMOL (22).

\section{Results}

Characterization of Mal polymorphisms in Japanese subjects. Eight polymorphisms were discovered in the 235-aa coding region of Mal (Fig. 1A). Four of these polymorphisms were already described in the NCBI, while the other four polymorphisms were novel [c.297 C>T (A99A), c.394 G>A (E132K), c.428 G>A (R143Q) and c.570 G>C (E190D)]. The three non-synonymous polymorphisms in the Mal gene [c.394 G>A (E132K), c.428 G>A (R143Q) and c.570 G>C (E190D)] are relatively rare missense variants. Two of three were only discovered in AD subjects (Table III). These three rare missense variants were found as heterozygotes. On the other hand, one of the synonymous SNPs, c.303 G>A (Q101Q) 


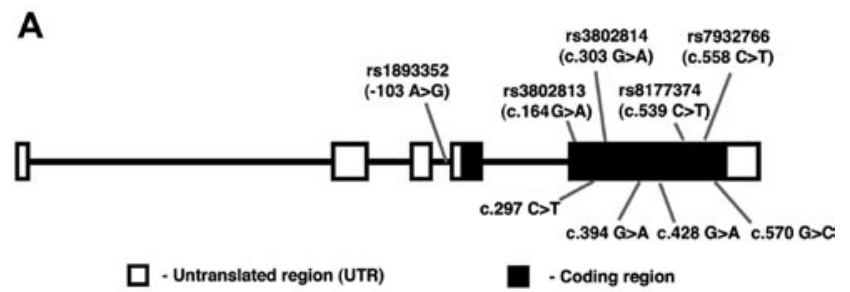

B

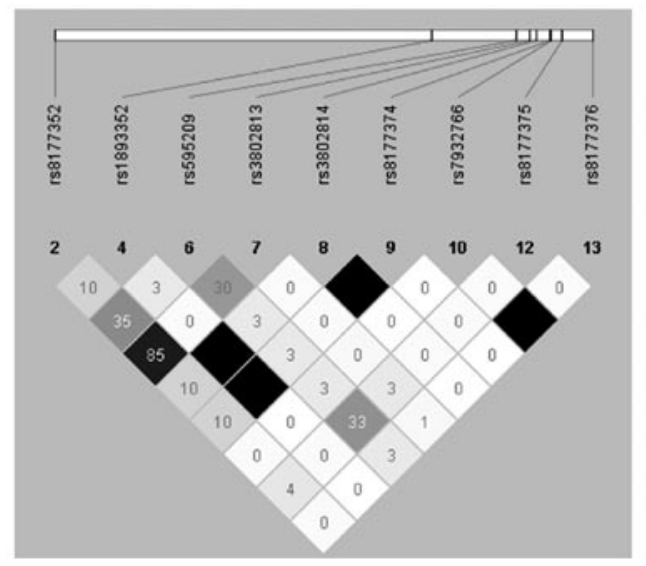

Figure 1. (A) Exon-intron structure of the Mal gene and locations of genotyped SNPs. c.297 C >T (A99A), c.394 G>A (E132K), c.428 G>A (R143Q) and c.570 G>C (E190D) are novel variants. The fragment of the genome containing the novel variants was sequenced for at least three times under different conditions to confirm that these novel variants are not PCR errors. (B) Linkage disequilibrium (LD) plot surrounding the Mal SNPs. The LD plot was generated by Haploview version 4.1 using the HapMap JPT database. The colors of the squares illustrate the magnitude of the pairwise $r^{2}$ values on a black and white scale, where black indicates a perfect $\operatorname{LD}\left(r^{2}=1.00\right)$. (rs3802814), was found at a significantly different frequency in the three categorized groups $(\mathrm{p}=0.038$, Table III). When we statistically tested the difference between AD and control groups, we found this SNP at a significantly lower frequency in $\mathrm{AD}$ subjects than in control subjects $(\mathrm{p}=0.016$, data not shown). We did not find a significant difference between the other allergic disease groups and the control group.

Functional analyses of synonymous and non-synonymous SNPs of Mal. Overexpression of wild-type Mal led to a strong induction of $\mathrm{NF}-\kappa \mathrm{B}$ reporter gene activity, and three of the studied polymorphisms (S55N, Q101Q and S180L) were comparable to wild-type Mal in their ability to activate $\mathrm{NF}-\kappa \mathrm{B}$. Interestingly, the variants E132K, R143Q and E190D were severely incompetent in $\mathrm{NF}-\kappa \mathrm{B}$ activation (Fig. 2A). The expression of E132K, R143Q and E190D variants in HEK 293T cells was confirmed by Western blotting (Fig. 2B).

The variants S55N, Q101Q and S180L produced comparable levels of TNF- $\alpha$ and IL-12 to the levels produced by wild-type Mal. However, E132K, R143Q and E190D did not produce TNF- $\alpha$ or IL-12 in the presence or absence of LPS (Fig. 2C). These analyses suggest that these three non-synonymous SNPs of Mal are loss-of-function variants.

Dose-dependent assays were performed to classify the mechanism of behavior of the variants E132K, R143Q and E190D. As shown in Fig. 4A, E132K showed a dominant negative inhibitory effect in LPS/TLR4 dependent activation of NF- $\kappa$ B, while R143Q and E190D did not show a significant dominant negative effect.
A

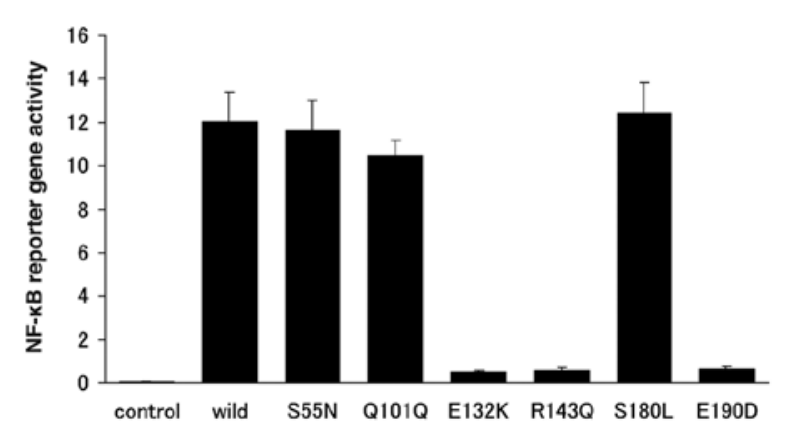

B

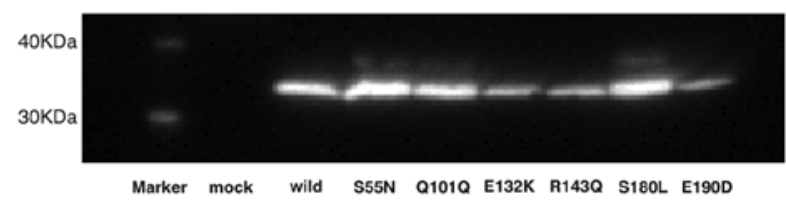

C
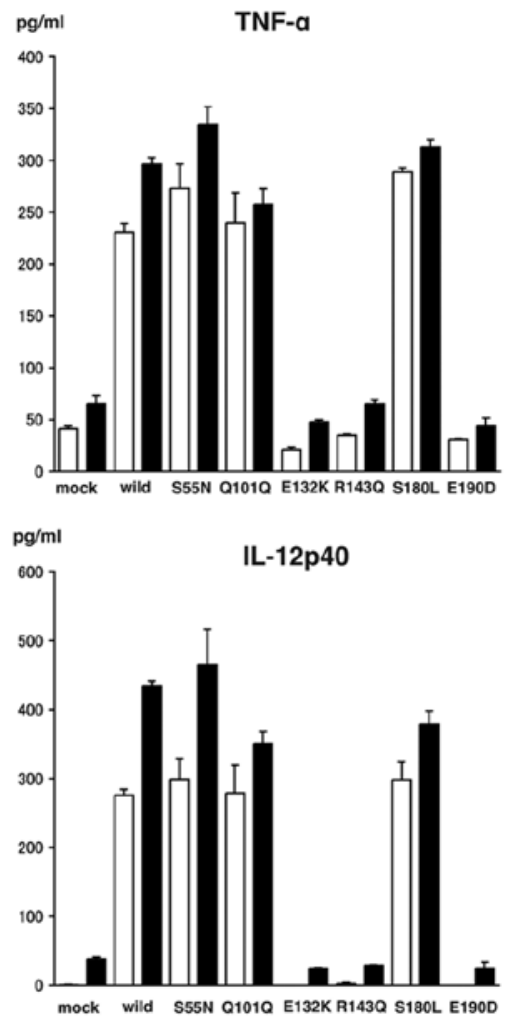

Figure 2. (A) Mal signaling induces NF-kB-driven reporter gene activity. HEK 293T cells were equally transfected with 100 ng vector DNA (pFLAG Mal wild-type or variants of Mal). (B) Protein expression levels of Mal variants. (C) TNF- $\alpha$ and IL-12 production assay. White bars show the cytokine production levels from THP-1 cells without LPS stimulation, black bars show cytokine production levels from LPS stimulated THP-1 cells. These results are shown as the mean of triplicate determinations \pm SD. 
Table III. Mal single nucleotide polymorphism (SNP) frequencies in the AD ( $n=99)$, other allergic diseases $(n=108)$ and control $(\mathrm{n}=103)$ groups.

\begin{tabular}{|c|c|c|c|c|c|c|}
\hline $\begin{array}{l}\text { SNP } \\
\text { (amino acid change) }\end{array}$ & dbSNP ID & Genotype & $\mathrm{AD}(\%)$ & $\begin{array}{c}\text { Other allergic } \\
\text { diseases }(\%)\end{array}$ & Controls (\%) & P-value \\
\hline $\begin{array}{l}\text { c. } 164 \mathrm{G}>\mathrm{A} \\
(\mathrm{S} 55 \mathrm{~N})\end{array}$ & rs3802813 & $\begin{array}{l}\text { GG } \\
\text { GA } \\
\text { AA }\end{array}$ & $\begin{array}{c}66(66.7) \\
32(32.3) \\
1(1.0)\end{array}$ & $\begin{array}{c}77(71.3) \\
29(26.85) \\
2(1.85)\end{array}$ & $\begin{array}{c}64(62.1) \\
39(37.9) \\
0\end{array}$ & 0.34 \\
\hline $\begin{array}{l}\text { c. } 297 \mathrm{C}>\mathrm{T} \\
(\mathrm{A} 99 \mathrm{~A})\end{array}$ & & $\begin{array}{l}\mathrm{CC} \\
\mathrm{CT} \\
\mathrm{TT}\end{array}$ & $\begin{array}{c}99(100) \\
0 \\
0\end{array}$ & $\begin{array}{c}107(99.1) \\
1(0.9) \\
0\end{array}$ & $\begin{array}{c}103(100) \\
0 \\
0\end{array}$ & 0.39 \\
\hline $\begin{array}{l}\text { c.303 G>A } \\
(\mathrm{Q} 101 \mathrm{Q})\end{array}$ & rs3802814 & $\begin{array}{l}\text { GG } \\
\text { GA } \\
\text { AA }\end{array}$ & $\begin{array}{c}91(91.9) \\
8(8.1) \\
0\end{array}$ & $\begin{array}{c}94(87.0) \\
14(13.0) \\
0\end{array}$ & $\begin{array}{c}82(79.6) \\
21(20.4) \\
0\end{array}$ & $0.038^{\mathrm{a}}$ \\
\hline $\begin{array}{l}\text { c. } 394 \mathrm{G}>\mathrm{A} \\
(\mathrm{E} 132 \mathrm{~K})\end{array}$ & & $\begin{array}{l}\text { GG } \\
\text { GA } \\
\text { AA }\end{array}$ & $\begin{array}{c}97(98.0) \\
2(2.0) \\
0\end{array}$ & $\begin{array}{c}108(100) \\
0 \\
0\end{array}$ & $\begin{array}{c}103(100) \\
0 \\
0\end{array}$ & 0.11 \\
\hline $\begin{array}{l}\text { c. } 428 \mathrm{G}>A \\
(\mathrm{R} 143 \mathrm{Q})\end{array}$ & & $\begin{array}{l}\text { GG } \\
\text { GA } \\
\text { AA }\end{array}$ & $\begin{array}{c}98(99.0) \\
1(1.0) \\
0\end{array}$ & $\begin{array}{c}108(100) \\
0 \\
0\end{array}$ & $\begin{array}{c}100(97.1) \\
3(2.9) \\
0\end{array}$ & 0.17 \\
\hline $\begin{array}{l}\text { c. } .539 \mathrm{C}>\mathrm{T} \\
(\mathrm{S} 180 \mathrm{~L})\end{array}$ & rs8177374 & $\begin{array}{l}\mathrm{CC} \\
\mathrm{CT} \\
\mathrm{TT}\end{array}$ & $\begin{array}{c}94(94.9) \\
5(5.1) \\
0\end{array}$ & $\begin{array}{c}104(96.3) \\
4(3.7) \\
0\end{array}$ & $\begin{array}{c}97(94.2) \\
6(5.8) \\
0\end{array}$ & 0.77 \\
\hline $\begin{array}{l}\text { c. } 558 \mathrm{C}>\mathrm{T} \\
(\mathrm{A} 186 \mathrm{~A})\end{array}$ & rs7932766 & $\begin{array}{l}\text { CC } \\
\text { CT } \\
\text { TT }\end{array}$ & $\begin{array}{c}89(89.9) \\
10(10.1) \\
0\end{array}$ & $\begin{array}{c}102(94.4) \\
5(4.6) \\
1(1.0)\end{array}$ & $\begin{array}{c}96(93.2) \\
7(6.8) \\
0\end{array}$ & 0.38 \\
\hline $\begin{array}{l}\text { c. } 570 \mathrm{G}>\mathrm{C} \\
(\mathrm{E} 190 \mathrm{D})\end{array}$ & & $\begin{array}{l}\text { GG } \\
\text { GC } \\
\text { CC }\end{array}$ & $\begin{array}{c}98(99.0) \\
1(1.0) \\
0\end{array}$ & $\begin{array}{c}108(100) \\
0 \\
0\end{array}$ & $\begin{array}{c}103(100) \\
0 \\
0\end{array}$ & 0.34 \\
\hline
\end{tabular}

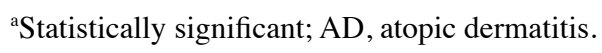

$-103 A>G$ and Q101Q are in LD. As displayed in Table III, the polymorphism Q101Q was found at a significantly lower frequency in the AD group. However, this polymorphism did not show a significantly higher ability than wild-type Mal in stimulating NF- $\kappa \mathrm{B}$ luciferase activity and producing inflammatory cytokines (Fig. 2). We searched the LD surrounding the Mal gene using the HapMap JPT database to detect any SNPs acting in LD with Q101Q. We found that the SNP -103 $\mathrm{A}>\mathrm{G}$ (rs1893352) shows complete LD $\left(\mathrm{r}^{2}=1.00\right)$ with Q101Q (rs3802814) (Fig. 1B). A luciferase reporter gene assay was performed to assess the functional effect of this SNP on the transcriptional ability of the Mal promoter. As shown in Fig. 3, the -103A allele significantly reduced the transcriptional activity of Mal $(\mathrm{p}=0.009)$, showing a 2.6-fold lower activity than the $-103 \mathrm{G}$ allele. Additionally, we found another SNP, S180L (rs8177374), to be in LD with Q101Q.

\section{Discussion}

Many SNPs in the Mal gene have been described, including A9P, R13W, S55N, D96N, Q101Q, D102H, S180L, A186A and V197I (23). Other polymorphisms have been found specifically in some ethnic groups, such as A100T, S131S and R143W in the coding region of Mal (24). With the SNPs discovered in our study (E132K, R143Q and E190D) added to this list, Mal can be considered a relatively polymorphic gene among TIR domain-containing adaptors (25).

In this study, we found Q101Q to be present at a significantly lower frequency in the AD group compared with control subjects. Though we could not explain the exact protective function of Q101Q, $-103 \mathrm{~A}>\mathrm{G}$ was found to be in LD with Q101Q and S180L, and the latter has been previously described as protective factor against bacterial infection (15). Thus, we speculate that Q101Q plays a protective role against the onset of atopic dermatitis via increasing transcriptional activity of Mal.

We searched for transcription factor binding sites in the promoter region of Mal by using Genomatix (http://www. genomatix.de/) to detect whether the polymorphism -103 $A>G$ acts to influence transcription factor. We found that one transcription factor associated with the Mal promoter, named CTCF, precisely binds to the nucleotide sequence 5 'tctctct ACCCtctgtaggatggctgc 3 ', in which the capital letters denote the core sequence used by MatInspector (Genomatix: Matrix Library information). The capital $\mathrm{A}$ in the core sequence is the $A$ allele of $-103 \mathrm{~A}>\mathrm{G}$. It has been reported that $\mathrm{CTCF}$ 
A

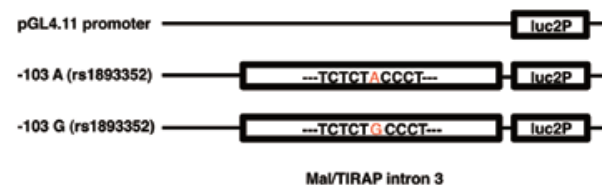

B

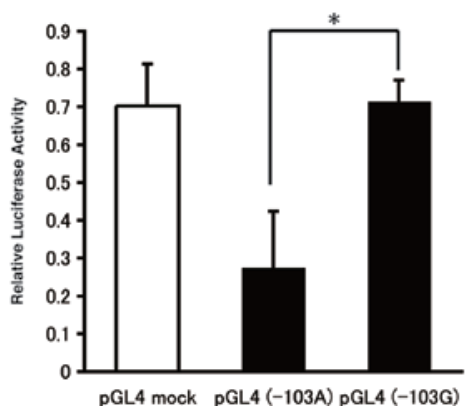

Figure 3. (A) pGL4 plasmid constructs used for transfection. (B) Transcriptional activities of the promoter of Mal with $-103 \mathrm{~A}>\mathrm{G}$ (rs1893352). THP-1 cells were transfected with the pGL4 vector as a control and the pGL4-Mal/-103A and pGL4-Mal/-103G variants. Transcriptional activities were measured by the luciferase reporter assay. Values of relative luciferase activity are shown as the means $\pm \mathrm{SD}$. ${ }^{*} \mathrm{P}=0.009$, Bonferroni test.

is a vertebrate insulator protein that blocks the interaction between enhancers and upstream promoters, thereby regulating imprinted expression (26). Therefore, we hypothesize that the variant $\mathrm{G}$ allele alters the CTCF binding site sequence and thus inhibits the binding of the insulator protein CTCF to the Mal promoter, thereby enhancing Mal transcriptional activity. This is consistent with the result of our transcriptional activity assay showing that the A allele of -103 has reduced activity compared with the G allele of -103 (Fig. 3).

S180L was the first identified functional SNP in Mal, as described by Khor et al (15). L180 led to a failure of Mal to interact with TLR2 but not MyD88. In contrast, Ferwerda et al showed increased production of proinflammatory cytokines (TNF, IL-6 and IFN- $\gamma$ ) in response to endotoxin in the S180L heterozygous individuals but not in S180 homozygous individuals (27). Although the overexpression assays of the S180L variants in this study and previously reported studies did not show differences in the activity between the wild-type Mal and S180L $(18,19)$, the linkage of S180L with Q101Q may be another modification factor for Q101Q.

The novel variants identified in this study (E132K, R143Q and E190D) all showed a significantly lower ability to activate NF- $\kappa \mathrm{B}$ and induce TNF- $\alpha$ and IL-12 (Fig. 2). IL-12 is an essential signal for the differentiation of naive Th cells into Th1 cells, which produce IFN- $\gamma$ and thereby inhibit Th2 differentiation and IgE production $(28,29)$. A failure to produce IL-12 can lead to allergic diseases. Because MyD88-dependent pathways are essential for the development of protective IL-12-mediated Th1 responses (30), a loss-of-function or a dominant-negative inhibitory effect of Mal may also lead to polarized Th2 responses, which could increase susceptibility to AD.

E132K is predicted to be located in the BB loop in the TIR domain of Mal (Fig. 4B). One of the important mutations of Mal, $\mathrm{P} 125 \mathrm{H}$, which is also located in the BB loop, has been found to fail to co-immunoprecipitate with TLR4 and to strongly inhibit activation of NF- $\mathrm{B}(2,3)$. Similarly, E132K is considered a critical residue located in the interaction region of the TIR domain. Interestingly, the E132K variant also showed a dominant-negative inhibitory effect in TLR4 signaling (2) (Fig. 4A). Moreover, this variant was found in two AD patients in this study, but was not found in the control subjects (Table III). These results suggest that the E132K variant may increase the risk of developing AD.

Our study found that the Mal variants R143Q and E190D also lead to loss-of-function (Figs. 2 and 4A). R143Q was found in both $\mathrm{AD}$ and control subjects, and we did not find a clear role for R143, but we hypothesize that R143Q affects the stability of the Mal protein, since R143 lies in a core position of the Mal TIR domain (Fig. 4B). The loss of the positively charged arginine in this polymorphism may affect the stability of Mal. On the other hand, in a novel feature that distinguishes Mal from MyD88, Mal has been found to possess a TRAF6 interaction motif, P-P-E-L-R-F, at amino acid position 188-193. This motif is essential for the signaling function of Mal. Mansell et al experimentally mutated the glutamic acid at position 190 to alanine and found that the mutant failed to induce TLR2- and TLR4-mediated activation of the NF- $\kappa \mathrm{B}, \mathrm{JNK}$ and MAP kinase pathways (6). These data suggest that E190D can inhibit NF- $\mathrm{B}$ activation and thereby may be associated with susceptibility to developing immunological diseases.
A

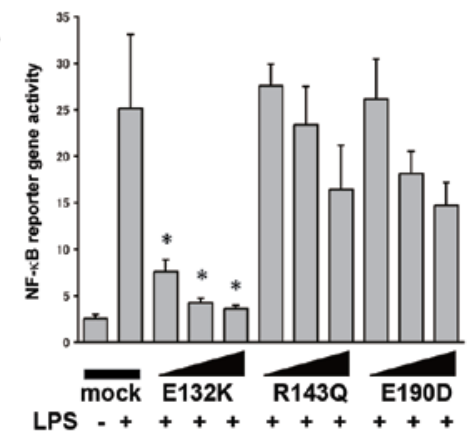

B

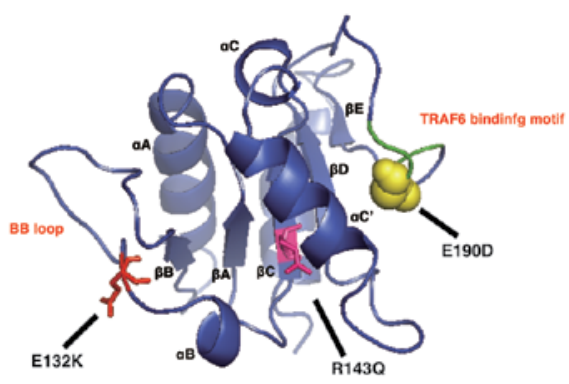

Figure 4. (A) The dose-dependent NF- $\mathrm{KB}$ reporter gene assay of Mal variants. Mal variants were cotransfected (10 ng, $40 \mathrm{ng}$, or $80 \mathrm{ng}$ ) in 293-hTLR4/ MD2-CD14 cells. E132K showed significant inhibition of LPS/TLR4-mediated NF- $\mathrm{BB}$ activation in a dose-dependent manner. "P<0.01. (B) Model structure of the Mal TIR domain. The illustrated structure was created from the protein structure of MyD88-TIR as a template. This structure comprised a central five-stranded parallel $\beta$-sheet ( $\beta \mathrm{A}-\beta \mathrm{E})$ surrounded by four $\alpha$-helices $(\alpha \mathrm{A}-\alpha \mathrm{C}$ and $\alpha \mathrm{E})$. The orientations of the side chain of E132 and $\mathrm{R} 143$ are shown with red or magenta color, respectively. The TRAF6 binding motif on Mal is highlighted with green and E190 is shown with yellow spheres. 
The TLR signaling pathways are crucial for the innate immune system to act in efficient host defense. Deletion mutations, compound heterozygous or homozygous missense mutations in MyD88 or IRAK4 have all been associated with immunodeficiency $(31,32)$. Recently, two MyD88 nonsynonymous SNPs were reported as loss-of-function variants (33). In addition, Mal knock-out mice have been shown to be susceptible to Klebsiella pneumonia (34). Therefore, it is likely that homozygosity or compound heterozygosity of the loss-offunction variants described in this study, which are located in TIR domain of Mal, could lead to immunodeficiency disorder due to an impaired innate immune response.

Efficient expression and appropriate function of Mal is necessary for the induction of sufficient proinflammatory cytokines and in initiating a timely Th1 immune response, thereby helping to balance Th2 and Th1 immune responses and defend against allergic diseases. The polymorphism -103 A>G, linked with Q101Q and/or S180L, may play a key protective role against atopic dermatitis. In contrast, dominant negative or loss-of-function variants in TIR domain of Mal could impair Mal-mediated signaling and lead to deficient production of proinflammatory cytokines, which may lead to $\mathrm{AD}$ or the other immunological disorders. The new identified polymorphisms and the functional characteristics described in our study may facilitate genetic diagnosis and lead to new therapies for atopic dermatitis.

\section{Acknowledgements}

This study was supported by Grants-in-Aid for Scientific Research from the Ministry of Education, Sports Science, Culture and Technology of Japan, by Health and Labour Science Research Grants for Research on Intractable Disease from the Ministry of Health, Labour and Welfare, Japan, and by Environmental Restoration and Conservation Agency of Japan.

\section{References}

1. Jenkins KA and Mansell A: TIR-containing adaptors in Toll-like receptor signaling. Cytokine 49: 237-244, 2010.

2. Horng T, Barton GM and Medzhitov R: TIRAP: an adapter molecule in the Toll signaling pathway. Nat Immunol 2: 835-841, 2001.

3. Fitzgerald KA, Palsson-McDermott EM, Bowie AG, et al: Mal (MyD88-adaptor-like) is required for Toll-like receptor-4 signal transduction. Nature 413: 78-83, 2001.

4. Kagan JC, Medzhitov R: Phosphoinositide-mediated adaptor recruitment controls Toll-like receptor signaling. Cell 125: 943-955, 2006.

5. Ohnishi H, Tochio H, Kato Z, et al: Structural basis for the multiple interactions of the MyD88 TIR domain in TLR4 signaling. Proc Natl Acad Sci USA 106: 10260-10265, 2009.

6. Mansell A, Brint E, Gould JA, O'Neill LA and Hertzog PJ: Mal interacts with tumor necrosis factor receptor-associated factor (TRAF)- 6 to mediate NF- $\kappa$ B activation by Toll-like receptor (TLR)-2 and TLR4. J Biol Chem 279: 37227-37230, 2004.

7. Romagnani S: Immunologic influences on allergy and the TH1/ TH2 balance. J Allergy Clin Immunol 113: 395-400, 2004.

8. Kaisho T, Hoshino K, Iwabe T, Takeuchi O, Yasui T and Akira S: Endotoxin can induce MyD88-deficient dendritic cells to support Th2 cell differentiation. Int Immunol 14: 695-700, 2002.

9. Mrabet-Dahbi S, Dalpke AH, Niebuhr M, et al: The Toll-like receptor 2 R753Q mutation modifies cytokine production and Toll-like receptor expression in atopic dermatitis. J Allergy Clin Immunol 121: 1013-1019, 2008.

10. Kormann MS, Ferstl R, Depner M, et al: Rare TLR2 mutations reduce TLR2 receptor function and can increase atopy risk. Allergy 64: 636-642, 2009.
11. Oh DY, Schumann RR, Hamann L, Neumann K, Worm M and Heine G: Association of the toll-like receptor 2 A-16934T promoter polymorphism with severe atopic dermatitis. Allergy 64: 1608-1615, 2009

12. Bottcher MF, Hmani-Aifa M, Lindstrom A, et al: A TLR4 polymorphism is associated with asthma and reduced lipopolysaccharide-induced interleukin-12 (p70) responses in Swedish children. J Allergy Clin Immunol 114: 561-567, 2004.

13. Tewfik MA, Bosse Y, Lemire M, et al: Polymorphisms in interleukin-1 receptor-associated kinase 4 are associated with total serum IgE. Allergy 64: 746-753, 2009.

14. Baldini M, Lohman IC, Halonen M, Erickson RP, Holt PG and Martinez FD: A Polymorphism* in the 5' flanking region of the CD14 gene is associated with circulating soluble CD14 levels and with total serum immunoglobulin E. Am J Respir Cell Mol Biol 20: 976-983, 1999.

15. Khor CC, Chapman SJ, Vannberg FO, et al: A Mal functional variant is associated with protection against invasive pneumococcal disease, bacteremia, malaria and tuberculosis. Nat Genet 39: 523-528, 2007.

16. Hawn TR, Dunstan SJ, Thwaites GE, et al: A polymorphism in Toll-interleukin 1 receptor domain containing adaptor protein is associated with susceptibility to meningeal tuberculosis. J Infect Dis 194: 1127-1134, 2006.

17. Nejentsev S, Thye T, Szeszko JS, et al: Analysis of association of the TIRAP (MAL) S180L variant and tuberculosis in three populations. Nat Genet 40: 261-262, 2008.

18. Nagpal K, Plantinga TS, Wong J, et al: A TIR domain variant of MyD88 adapter-like (Mal)/TIRAP results in loss of MyD88 binding and reduced TLR2/TLR4 signaling. J Biol Chem 284: 25742-25748, 2009.

19. George J, Kubarenko AV, Rautanen A, et al: MyD88 adaptorlike D96N is a naturally occurring loss-of-function variant of TIRAP. J Immunol 184: 3025-3032, 2010.

20. Hanifin JM: Atopic dermatitis. J Allergy Clin Immunol 73: 211-226, 1984.

21. International HapMap Consortium. The International HapMap Project. Nature 426: 789-796, 2003.

22. Delano WL: The PyMol Molecular Graphics System 2002. Available from http://www.pymol.org/.

23. Database, Single Nucleotide Polymorphisms, National Center for Biotechnology Information. Available from http://www.ncbi. nlm.nih.gov/projects/SNP.

24. Dissanayeke SR, Levin S, Pienaar S, et al: Polymorphic variation in TIRAP is not associated with susceptibility to childhood TB but may determine susceptibility to TBM in some ethnic groups. PloS One 4: e6698, 2009.

25. Sheedy FJ and O'Neill LA: The Troll in Toll: Mal and Tram as bridges for TLR2 and TLR4 signaling. J Leukoc Biol 82: 196-203, 2007.

26. Kim TH, Abdullaev ZK, Smith AD, et al: Analysis of the vertebrate insulator protein CTCF binding sites in the human genome. Cell 128: 1231-1245, 2007.

27. Ferwerda B, Alonso S, Banahan K, et al: Functional and genetic evidence that the Mal/TIRAP allele variant 180L has been selected by providing protection against septic shock. Proc Natl Acad Sci USA 106: 10272-10277, 2009.

28. Macatonia SE, Hosken NA, Litton M, et al: Dendritic cells produce IL-12 and direct the development of Th1 cells from naive CD4 ${ }^{+} \mathrm{T}$ cells. J Immunol 154: 5071-5079, 1995.

29. Pene J, Rousset F, Briere F, et al: IgE production by normal human lymphocytes is induced by interleukin 4 and suppressed by interferons gamma and alpha and prostaglandin E2. Proc Natl Acad Sci USA 85: 6880-6884, 1988.

30. Muraille E, De Trez C, Brait M, De Baetselier P, Leo O and Carlier Y: Genetically resistant mice lacking MyD88-adapter protein display a high susceptibility to Leishmania major infection associated with a polarized Th2 response. J Immunol 170: 4237-4241, 2003

31. Von Bernuth H,Picard C, Jin Z, et al: Pyogenic bacterial infections in humans with MyD88 deficiency. Science 321: 691-696, 2008.

32. Picard C, Puel A, Bonnet M, et al: Pyogenic bacterial infections in humans with IRAK-4 deficiency. Science 299: 2076-2079, 2003.

33. George J, Motshwene PG, Wang H, et al: Two human MYD88 variants, S34Y and R98C, interfere with MyD88-IRAK4myddosome assembly. J Biol Chem 286: 1341-1353, 2011.

34. Jeyaseelan S, Young SK, Yamamoto M, Arndt PG, Akira S, Kolls JK and Worthen GS: Toll/IL-1R domain-containing adaptor protein (TIRAP) is a critical mediator of antibacterial defense in the lung against Klebsiella pneumoniae but not Pseudomonas aeruginosa. J Immunol 177: 538-547, 2006. 